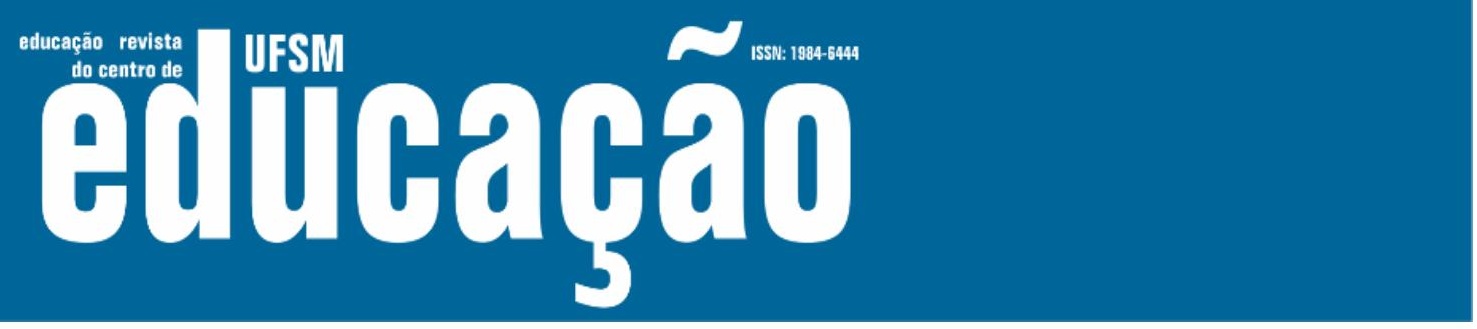

ISSN: 1984-6444 | http://dx.doi.org/10.5902/1984644440261

\title{
O direito à educação no atendimento escolar hospitalar e domiciliar: inquietações conceituais e legais
}

\author{
The right to education in hospital and home schooling: conceptual and \\ legal concerns
}

Cinthya Vernizi Adachi de Menezes

Professora doutora da FAE Centro Universitário, Curitiba, Paraná, Brasil. cinthya.menezes@fae.edu - https://orcid.org/0000-0001-9073-1664

Rose Meri Trojan

Professora aposentada da Universidade Federal do Paraná, Curitiba, Paraná, Brasil. rosetrojan@uol.com.br - https://orcid.org/0000-0002-7619-5508

Ercilia Maria Angeli Teixeira de Paula

Professora doutora da Universidade Estadual de Maringá. Maringá, Paraná, Brasil. erciliaangeli@yahoo.com.br - https://orcid.org/0000-0002-8619-7558

Recebido em 30 de setembro de 2019

Aprovado em 27 de janeiro de 2020

Publicado em 20 de março de 2020

\section{RESUMO}

Este estudo trata sobre o direito ao atendimento escolar em ambiente hospitalar e domiciliar, para estudantes impossibilitados de frequentar a escola regular por motivo de tratamento de saúde, a partir da legislação vigente. O objetivo é analisar os principais documentos que normatizam 0 atendimento escolar hospitalar e domiciliar no Brasil, a partir dos conceitos que estabelecem o direito à educação básica e obrigatória. Embora se refira a uma área de conhecimento já fortalecida, se faz necessário refletir sobre as implicações das políticas educacionais para a garantia, ou não, de acesso à escola para esta demanda social. A metodologia fundamenta-se em uma pesquisa documental e bibliográfica para estabelecer as bases legais e conceituais necessárias para analisar o tema. As análises dos resultados assinalam para a importância das ações voltadas à garantia da continuidade do processo de escolarização realizado em ambiente hospitalar e domiciliar, pois se entende que a condição do enfrentamento da doença não pode se caracterizar como proibitivo do acesso à educação, que é direito público subjetivo, fundamental e constitucional na perspectiva inclusiva.

Palavras-chave: Atendimento Escolar Hospitalar e Domiciliar; Direitos Humanos e Cidadania; Direito à Educação.

\section{ABSTRACT}

This study is about the right to hospital and homeschooling to students who are not able to attend school for health treatment reasons, discussed and analyzed from the 


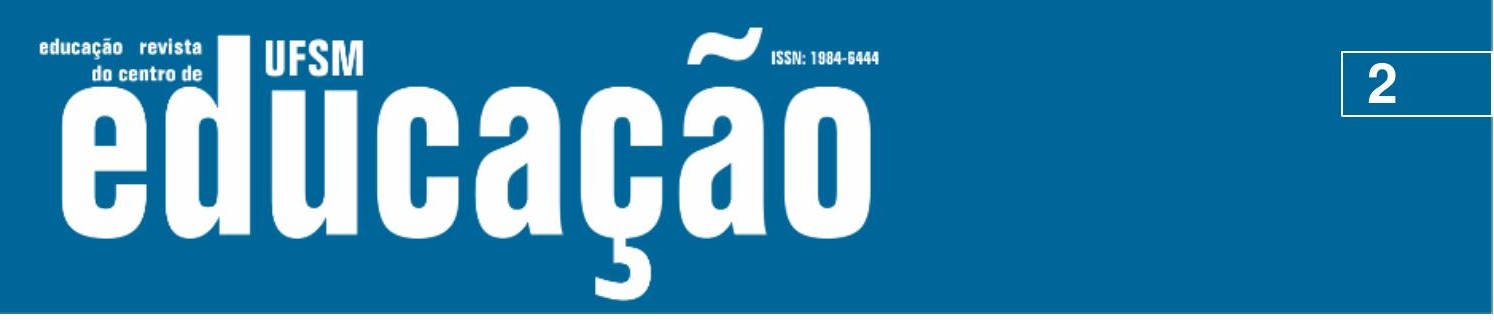

ISSN: 1984-6444 | http://dx.doi.org/10.5902/1984644440261

perspective in accordance with the legislation in force. The purpose of this paper is to analyze the main documents that regulate hospital and home schooling in Brazil, based on the concepts that set forth the right to basic and compulsory education. Although it is a consolidated area of knowledge, reflecting on the implications of educational policies to guarantee or not access to school is crucial for this social demand. The methodology of this research is based on a documental and bibliographic research to establish the necessary legal and conceptual bases to analyze the theme. The analyses of the results indicate the importance of actions aimed at guaranteeing the continuity of the schooling process carried out in hospital and home environments, since it is understood that confront the disease cannot impede access to education, which is subjective public, fundamental and constitutional right from the inclusive perspective.

Keywords: Hospital Schooling and Homeschooling; Human Rights and Citizenship; Right to Education.

\section{Introdução}

Este estudo apresenta uma análise acerca do direito ao atendimento escolar em ambiente hospitalar e domiciliar, para estudantes impossibilitados de frequentar a escola regular por motivo de tratamento de saúde. O escopo deste refere-se aos dispositivos conceituais e legais vigentes no Brasil, que têm como objetivo amparar e promover o acesso à educação básica com vistas à continuidade do processo ensino-aprendizagem nesta especial condição. Neste sentido, entendese que a educação formal, mesmo ocorrendo em espaços não escolares, pode ser considerada "uma dimensão fundante da cidadania, e tal princípio é indispensável para políticas que visam à participação de todos nos espaços sociais e políticos e, mesmo, para reinserção no mundo profissional" (CURY, 2002, p. 246).

Ao discutir o conceito do estudante em tratamento de saúde ${ }^{1}$ essa pesquisa considera a educação a partir do preceito constitucional que a institui enquanto direito público subjetivo, ou seja, há prerrogativa da oferta exigida ao estado, mesmo na condição de afastamento involuntário causado por motivos de doença. Nesse contexto, se desenvolve no texto o conceito desse direito social juntamente ao conceito de direito humano e de cidadania, vinculados ao ordenamento jurídico e político existente e a prescrição sobre a igualdade de 


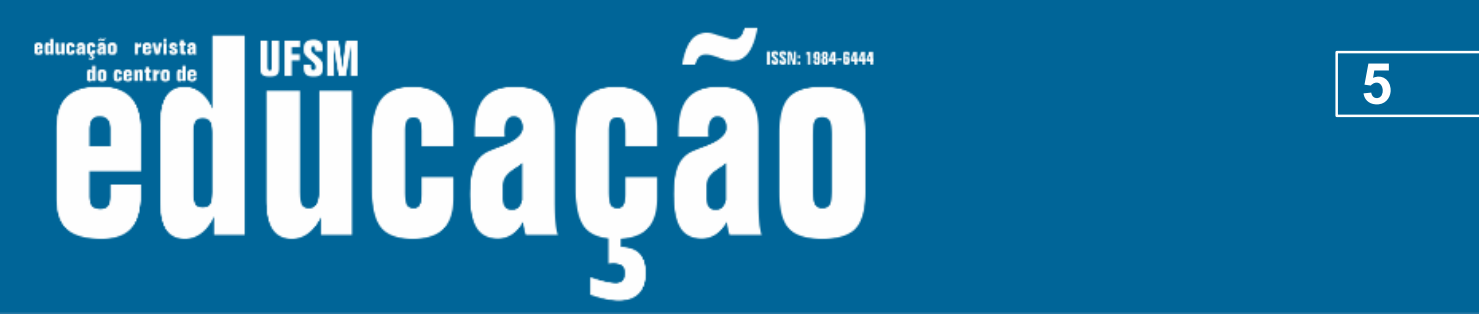

ISSN: 1984-6444 | http://dx.doi.org/10.5902/1984644440261

é considerada pelas autoras como a última normativa da área da Educação Especial que versa sobre a inclusão educacional.

Quadro 2 - Documentos legais da área da educação especial (1969 a 2015)

\begin{tabular}{|c|c|c|}
\hline ANO & DOCUMENTO & OBJETIVO \\
\hline 1969 & $\begin{array}{l}\text { Lei } \mathrm{n}^{\circ} 1.044, \text { de } 21 \mathrm{de} \\
\text { outubro de } 1969 .\end{array}$ & $\begin{array}{l}\text { Dispor sobre o tratamento excepcional para os alunos } \\
\text { portadores de afeç̧ões. }\end{array}$ \\
\hline 1975 & $\begin{array}{l}\text { Lei } n^{\circ} 6.202 \text {, de } 17 \text { de } \\
\text { abril de } 1975 \text {. }\end{array}$ & 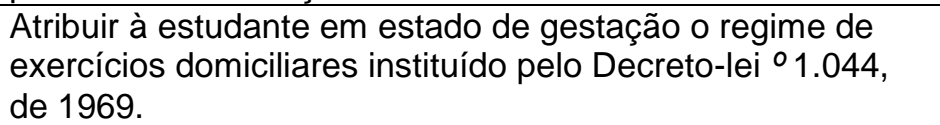 \\
\hline 2001 & $\begin{array}{l}\text { Resolução CNE/CEB № } \\
2 \text {, de } 11 \text { de setembro } \\
\text { de } 2001\end{array}$ & $\begin{array}{l}\text { Instituir Diretrizes Nacionais para a Educação Especial na } \\
\text { Educação Básica. }\end{array}$ \\
\hline 2001 & $\begin{array}{l}\text { Parecer CNE/CEB no } \\
\text { 17/2001, aprovado em } \\
3 \text { de julho de } 2001\end{array}$ & $\begin{array}{l}\text { Emitir parecer sobre as Diretrizes Nacionais para a } \\
\text { Educação Especial na Educação Básica. }\end{array}$ \\
\hline 2008 & $\begin{array}{l}\text { Decreto № } 6.571 \text {, de } 17 \\
\text { de setembro de } 2008 \text {. }\end{array}$ & $\begin{array}{l}\text { Dispor sobre o atendimento educacional especializado, } \\
\text { regulamenta o parágrafo único do art. } 60 \text { da lei } n^{\circ} 9.394 \text {, de } \\
20 \text { de dezembro de } 1996 \text {, e acrescenta dispositivo ao } \\
\text { decreto } n^{\circ} 6.253 \text {, de } 13 \text { de novembro de } 2007 \text {.(Revogado.) }\end{array}$ \\
\hline 2009 & $\begin{array}{l}\text { Resolução } n^{\circ} 04 / 09 \text {, de } \\
2 \text { de outubro de } 2009 \text {. }\end{array}$ & $\begin{array}{l}\text { Instituir Diretrizes Operacionais para o Atendimento } \\
\text { Educacional Especializado na Educação Básica, } \\
\text { modalidade Educação Especial. }\end{array}$ \\
\hline 2009 & $\begin{array}{l}\text { Parecer CNE/CEB } n^{\circ} \\
13 / 2009, \text { aprovado em } \\
03 \text { de junho de } 2009\end{array}$ & $\begin{array}{l}\text { Emitir parecer sobre as Diretrizes Operacionais para o } \\
\text { atendimento educacional especializado na Educação } \\
\text { Básica, modalidade Educação Especial. }\end{array}$ \\
\hline 2011 & $\begin{array}{l}\text { Decreto № } 7.611 / 11 \text {, de } \\
17 \text { de novembro de } \\
2011 \text {. }\end{array}$ & $\begin{array}{l}\text { Dispor sobre a Educação Especial, o Atendimento } \\
\text { Educacional Especializado. }\end{array}$ \\
\hline 2011 & $\begin{array}{l}\text { Decreto } n^{0} 7.612 / 11 \text {, de } \\
17 \text { de novembro de } \\
2011 .\end{array}$ & $\begin{array}{l}\text { Instituir o Plano Nacional dos Direitos da Pessoa com } \\
\text { deficiência - Plano Viver sem Limite. }\end{array}$ \\
\hline 2015 & $\begin{array}{l}\text { Lei n.o } 13.146 / 15 \\
\text { Lei Brasileira de } \\
\text { Inclusão da Pessoa } \\
\text { com Deficiência } \\
\text { (Estatuto da Pessoa } \\
\text { com Deficiência), }\end{array}$ & $\begin{array}{l}\text { Assegurar e promover, em condições de igualdade, o } \\
\text { exercício dos direitos e das liberdades fundamentais da } \\
\text { pessoa com deficiência, visando à sua inclusão social e } \\
\text { cidadania. }\end{array}$ \\
\hline
\end{tabular}

Fonte: Portal da Legislação (BRASIL), MEC. Elaborado pelas autoras.

Dessa forma, esta metodologia permite analisar em que medida o arcabouço legal adota conceitos, termos e prescrições indicadas pelos pesquisadores da área, o que pode servir de base para várias investigações sobre o assunto. 


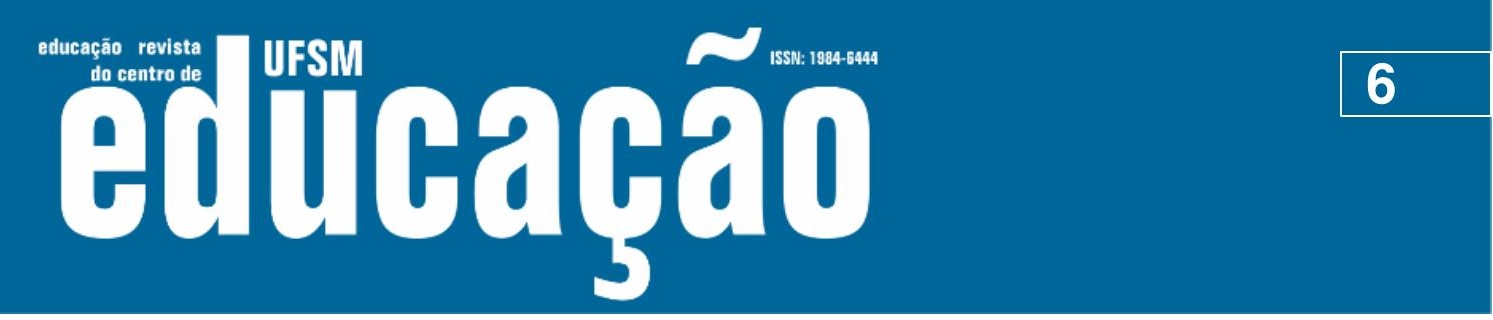

ISSN: 1984-6444 | http://dx.doi.org/10.5902/1984644440261

\section{Resultados e discussão}

\section{As leis que amparam o atendimento escolar hospitalar e domiciliar: um resgate histórico}

Para subsidiar, sob o ponto de vista jurídico, a garantia do direito à educação do estudante em tratamento de saúde, o mote é conhecer os principais documentos legais e suas atualizações ${ }^{4}$ que regulamentam a educação nacional, de forma mais ampla, e as normativas da área de Educação Especial, que se referem ao tema em foco.

Parte-se do pressuposto que a Constituição Federal (CF), Artigo 6, garante que educação é direito de todo cidadão e dever do Estado (BRASIL, 1988), devendo ser afiançado por meio de políticas sociais que tenham por objetivo a igualdade de condições para acesso, permanência e sucesso na escola.

A declaração do direito à educação estabelecida no texto constitucional de 1988 criou as condições para a expansão dos últimos anos, permitindo redefinir-se as prioridades na luta pela expansão desse direito. [...] Hoje, sua generalização cria as condições para a necessária atualização do próprio texto constitucional. (OLIVEIRA; ARAÚJO, 2005, p.21)

Contudo, ainda que as legislações vigentes demonstrem avanços para regulamentar o atendimento aos estudantes em tratamento de saúde, há escassez de políticas públicas que garantam a efetivação do atendimento escolar em ambiente hospitalar e domiciliar. Nessa perspectiva, iniciativas desse atendimento estão legalmente amparadas por normatizações que, cada vez mais, enfatizam o sujeito enquanto cidadão de direitos.

O Decreto-Lei n. 1044, de 21 de outubro de 1969 (BRASIL, 1969), ainda em vigência, apresenta em seus artigos iniciais considerações que ressaltam as formas de atendimento escolar na impossibilidade de frequência à escola regular, os quais regulamentam a necessidade de

[...] tratamento excepcional para os alunos, de qualquer nível de ensino, portadores de afecções congênitas ou adquiridas, infecções, traumatismo ou outras condições mórbidas, determinando distúrbios agudos, caracterizados pela incapacidade física relativa, incompatível com a frequência aos trabalhos escolares, desde que se verifique a conservação das condições intelectuais e emocionais necessárias para o prosseguimento da atividade escolar em novos moldes. A atribuição a esses estudantes, 


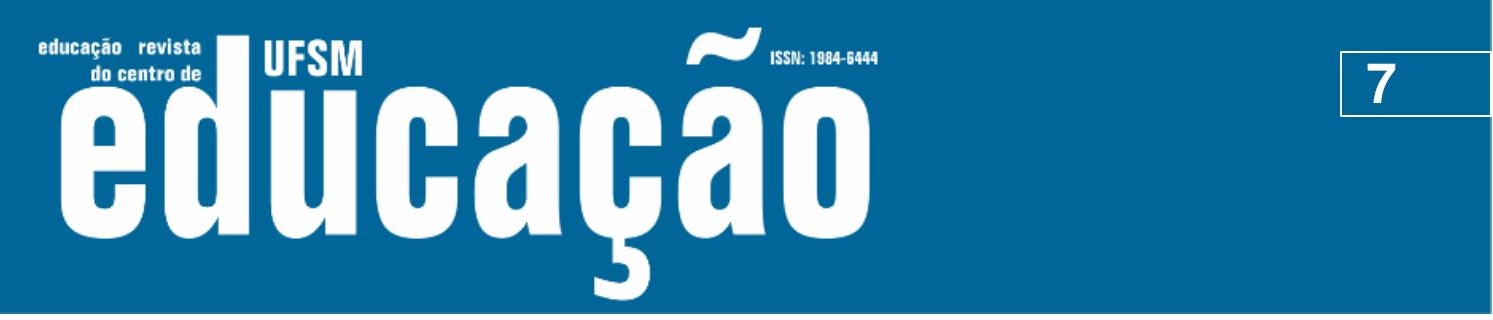

ISSN: 1984-6444 | http://dx.doi.org/10.5902/1984644440261

como compensação da ausência às aulas, o exercício domiciliares com acompanhamento da escola, sempre que compatíveis com o seu estado de saúde e as possibilidades do estabelecimento. (BRASIL, 1969)

Mais tarde, a Lei n. 6.202, de 17 de abril de 1975 (BRASIL, 1975), atribui às estudantes em gestação, o regime de exercícios domiciliares e o direito à realização de exames finais, protegendo o direito à continuidade dos estudos nessa condição de afastamento.

No ano de 1990, é regulamentado o artigo 227 da CF, que versa sobre o "dever da família, da sociedade e do Estado" de assegurar direitos à criança, ao adolescente e ao jovem, por meio do Estatuto da Criança e do Adolescente - ECA (BRASIL, 1990), incluindo a educação:

Art. 4ํ - É dever da família, da comunidade, da sociedade em geral e do Poder Público assegurar, com absoluta prioridade, a efetivação dos direitos referentes à vida, à saúde, à alimentação, à educação, ao esporte, ao lazer, à profissionalização, à cultura, à dignidade, ao respeito, à liberdade e à convivência familiar e comunitária. (BRASIL, 1990)

Em 1995, a Resolução nํ 41 do Conselho Nacional dos Direitos da Criança e do Adolescente - CONANDA, baseada em documento elaborado pela Sociedade Brasileira de Pediatria, institui vinte direitos da criança e do adolescente hospitalizado (BRASIL, 1995). O artigo $9^{\circ}$ estabelece o "direito a desfrutar de alguma forma de recreação, programas de educação para saúde, acompanhamento do curriculum escolar, durante sua permanência hospitalar" (BRASIL, 1995).

Mas, somente com a lei 13.716/2018 (BRASIL, 2018), houve a inclusão do direito específico na Lei de Diretrizes e Bases da Educação:

Art. 4ํ- A. É assegurado atendimento educacional, durante o período de internação, ao aluno da educação básica internado para tratamento de saúde em regime hospitalar ou domiciliar por tempo prolongado, conforme dispuser o Poder Público em regulamento, na esfera de sua competência federativa. (BRASIL, 1996)

Mesmo com a inserção legal do direito, não houve a especificação dos termos conceituais identificados nas normativas do atendimento escolar hospitalar e domiciliar: classe hospitalar ${ }^{5}$ e atendimento pedagógico domiciliar ${ }^{6}$. Ainda assim, desde 2001, nas Diretrizes Nacionais para a Educação Especial na Educação Básica, Resolução 02/2001 - CNE/CNB (BRASIL, 2001b), os estudantes em 


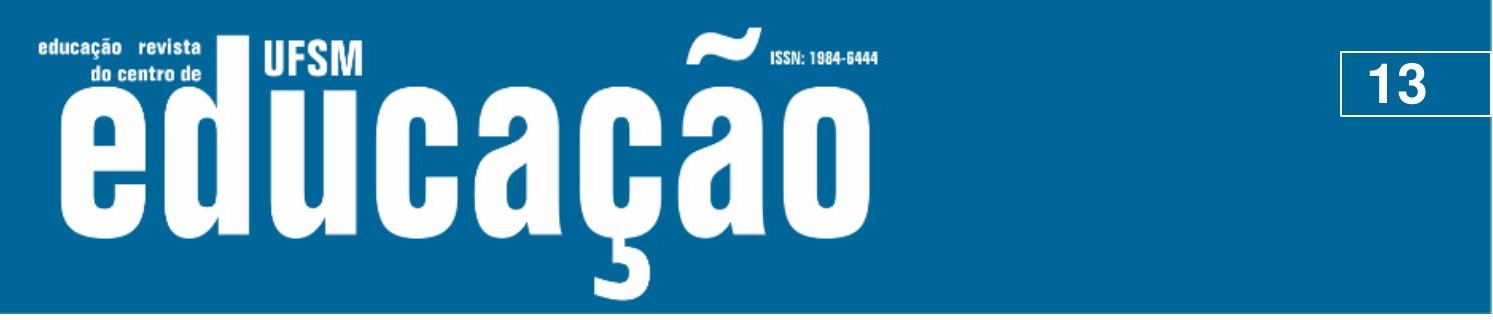

ISSN: 1984-6444 | http://dx.doi.org/10.5902/1984644440261

instituições de ensino e pesquisa, nos movimentos sociais e organizações da sociedade civil e nas manifestações culturais." (BRASIL, 1996). Para tanto, reiterando o artigo 206 da CF, o artigo $3^{\circ}$ da LDBEN destaca que o ensino deverá ser pautado nos seguintes princípios:

I - igualdade de condições para o acesso e permanência na escola; II liberdade de aprender, ensinar, pesquisar e divulgar a cultura, o pensamento, a arte e o saber; III - pluralismo de ideias e de concepções pedagógicas; IV - respeito à liberdade e apreço à tolerância; V coexistência de instituições públicas e privadas de ensino; VI - gratuidade do ensino público em estabelecimentos oficiais; VII - valorização do profissional da educação escolar; VIII - gestão democrática do ensino público, na forma desta Lei e da legislação dos sistemas de ensino; IX garantia de padrão de qualidade; $X$ - valorização da experiência extraescolar; XI - vinculação entre a educação escolar, o trabalho e as práticas sociais; e, XII - consideração com a diversidade étnico-racial. (BRASIL, 1996)

De acordo com os princípios apontados, a educação deve ser estendida aos estudantes em tratamento de saúde, independente do tipo de enfermidade constatada. Não há como estabelecer critérios para que o direito se efetive, como por exemplo, possibilitar o atendimento escolar para aquele que tenha contraído uma doença menos grave e com possibilidades de melhora do quadro clínico em um período de tempo menor. Desta forma,

A política democrática, depois que derrubamos todos os predomínios errados, é um convite perene a agir em público e a reconhecer-se como cidadão, capaz de escolher destinos e assumir riscos por si e pelos outros, e capaz, também, de patrulhar os limites da distribuição e sustentar uma sociedade justa. (...) E o predomínio da cidadania, ao contrário do predomínio da graça (ou do dinheiro, dos cargos públicos, da educação, ou da linhagem), não é tirânico; é o fim da tirania. (WALZER, 2008, p. 427)

A luta pela garantia dos direitos humanos deve estar atrelada à luta da pela cidadania para buscar o cumprimento do direito declarado. Mas há que se considerar que a desigualdade social se reflete nas discriminações e, portanto, distancia a igualdade política de sua efetividade.

Luta por inscrições mais democráticas, por efetivações mais realistas, contra descaracterizações mutiladoras, por sonhos de justiça. Todo o avanço da educação escolar além do ensino primário foi fruto de lutas conduzidas por uma concepção democrática da sociedade em que se postula ou a igualdade de oportunidades ou mesmo a igualdade de condições sociais. (CURY, 2002, p. 247) 


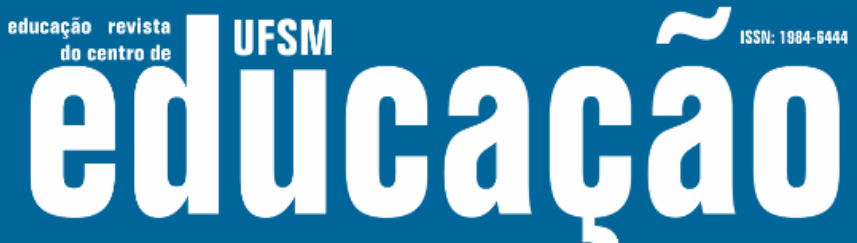

ISSN: 1984-6444 | http://dx.doi.org/10.5902/1984644440261

serviço, o público-alvo, seleção e formação dos professores, recursos pedagógicos, de infraestrutura e financeiros, bem como as atribuições de cada envolvido no processo. Assim, é imprescindível que haja uma parceria entre o Ministério da Educação e o Ministério da Saúde do governo brasileiro para que se estabeleçam as responsabilidades de cada pasta visando à implantação de uma política em conjunto.

Concomitante a prerrogativa da oferta dos serviços vinculados ao atendimento escolar hospitalar e domiciliar, reservada aos estados e municípios, deve-se ter clareza conceitual no tocante às concepções adotadas. A lei brasileira necessita de uma revisão urgente, pois o Decreto 1044/1969 (BRASIL, 1969), ainda vigente, segrega o direito de muitos ao definir quais são as doenças que acometem os estudantes em tratamento de saúde e que condicionam, portanto, o acesso escolar àqueles identificados no texto do decreto. Inclui também a questão do tempo "máximo admissível", sendo que o direito à educação deve ser garantido independentemente da duração do tratamento ao qual o estudante deve ser submetido.

\section{Conclusão}

A partir do exposto, identificam-se abordagens e concepções do atendimento escolar hospitalar e domiciliar que, buscando garantir o direito fundamental à educação ao estudante em tratamento de saúde, volta-se para o estabelecimento de políticas públicas que objetivam, segundo Tomasevski (2004, p. 349-350) obrigações estatais: a disponibilidade para assegurar a educação obrigatória a todos, respeitando inclusive as minorias afastadas da escola; a acessibilidade, abrangendo as distintas modalidades em cada nível de ensino; a aceitabilidade, englobando um conjunto de critérios voltados de qualidade da educação e a adaptabilidade, salvaguardando que as escolas devem se adaptar às necessidades dos alunos. Assim, o presente estudo buscou resgatar historicamente a legislação sobre o assunto, bem como apontar conceitos que permeiam as implicações para a efetivação do direito. 


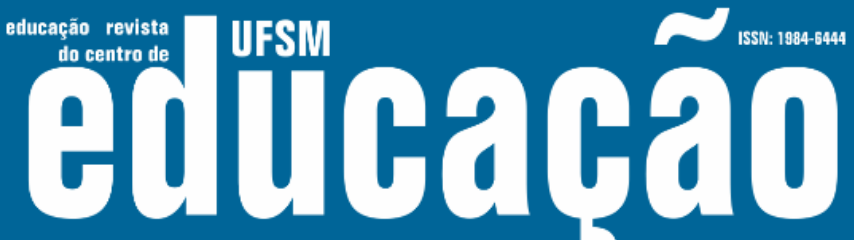

ISSN: 1984-6444 | http://dx.doi.org/10.5902/1984644440261

Apesar de, historicamente, as pesquisas sobre esta temática e a busca pelo reconhecimento do processo ensino-aprendizagem realizado no ambiente hospitalar e domiciliar estarem vinculados à área da Educação Especial, os principais documentos legais estudados não contemplam explicitamente as características do estudante em tratamento de saúde e de seu processo de escolarização. No entanto, as políticas públicas de atendimento ao alunado em situação de enfrentamento de doenças, devem refletir um entendimento de que deve ser garantida a educação como direito fundamental do cidadão e, portanto, este é um público que deve ser considerado como alvo da inclusão social e educacional.

Conforme foi apontado, o direito à educação do estudante em tratamento de saúde está reconhecido legalmente e, por meio deste amparo, há a possibilidade de se lutar por sua efetivação. As contradições ocorrem neste limite. A partir do momento que está declarado, o direito passa a ser especificado e a não oferta pode ser considerada um retrocesso social. Silveira (2013, p.383) aponta que quando se discute a educação como direito social deve-se atrelá-la a um direito fundamental de cada sujeito.

Aqui, segundo a autora, cabe ao cidadão se organizar para exigir o cumprimento do que de fato esteja declarado, onde a exigibilidade pode ocorrer por meio da pressão social, da atuação política ou institucional, por meio da participação em conselhos e comissões públicas, monitoramento do orçamento e das ações dos poderes públicos, de mecanismos de democracia participativa como plebiscito, referendo e iniciativa popular; recorrendo à estrutura administrativa da esfera educacional, a advogados e também aos seguintes órgãos: Conselho Tutelar; Comissões Legislativas de Direitos Humanos, Educação e Criança e Adolescente; Ouvidorias Públicas, Ministério Público, Defensoria Pública e Poder Judiciário.

Desta forma, a prática pedagógica realizada em ambiente hospitalar e domiciliar, para além de considerar as especificidades dos diferentes contextos que envolvem os estudantes em tratamento de saúde, contribui para a garantia do processo de democratização e universalização do ensino obrigatório. 


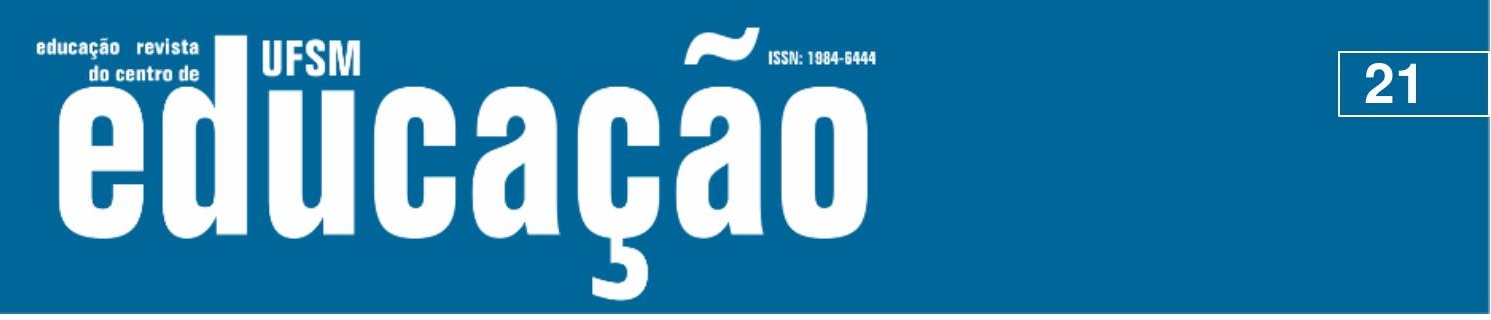

ISSN: 1984-6444 | http://dx.doi.org/10.5902/1984644440261

\section{Referências}

ABRAMOVICH, Victor. Linhas de trabalho em direitos econômicos, sociais e culturais: instrumentos e aliados. SUR - Revista Internacional de Direitos Humanos. São Paulo, Ano 2, número 2, 2005. Disponível em: http://dx.doi.org/10.1590/S1806-64452005000100009 Acesso em: 03 jan. 2018.

BARROS, Alessandra. Panorama da classe hospitalar no mundo. In: DIAZ, Félix. et al (orgs). Educação inclusiva, deficiência e contexto social: questões contemporâneas. Salvador: EDUFBA, 2009. cap. 25, p. 279 - 288.

BRASIL. Congresso Nacional. Lei $\mathbf{n}^{\circ} \mathbf{1 . 0 4 4}$, de 21 de outubro de 1969. Brasília, 1969. Disponível em http://www.planalto.gov.br/ccivil_03/decreto-lei/del1044.htm. Acesso em: 05 abr. 2013.

BRASIL. Lei $\mathbf{n}^{\circ}$ 6.202, de 17 de abril de 1975. Brasília, 1975. Disponível em: http://www.planalto.gov.br/ccivil_03/leis/1970-1979/16202.htm. Acesso em: 05 abr. 2013.

BRASIL. Congresso Nacional. Constituição da República Federativa do Brasil de $1988 . \quad$ Brasília, $1988 . \quad$ Disponível em: http://www.jusbrasil.com.br/noticias/busca?q=Artigo+205\%2C+Constitui\%C3\%A7\%C 3\%A3o+Federal+de+1988\&s=noticias. Acesso em: 05 abr. 2013.

BRASIL. Congresso Nacional. Lei $\mathbf{n}^{\circ} \mathbf{8 . 0 6 9}$, de 13 de Julho de 1990. Brasília, 1990. Disponível em: http://www.planalto.gov.br/ccivil_03/leis/18069.htm. Acesso em: 06 abr. 2013.

BRASIL. CONANDA. Conselho Nacional dos Direitos da Criança e do Adolescente. Resolução $n^{\circ} 41$, de 17 de outubro de 1995. Brasília, 1995. Disponível em http://www.mp.rs.gov.br/infancia/legislacao/id2178.htm. Acesso em: 06 abr. 2013.

BRASIL. Congresso Nacional. Lei $\mathbf{n}^{\circ}$ 9.394, de 20 de dezembro de 1996. Brasília, 1996. Disponível em http://www.planalto.gov.br/ccivil_03/leis/19394.htm. Acesso em: 08 abr. 2013.

BRASIL. Conselho Nacional de Educação. Parecer CNE/CEB n 06, de 07 de abril de 1998. Brasília, $1998 . \quad$ Disponível em: http://siau.edunet.sp.gov.br/ItemLise/arquivos/notas/parcne6_98.htm. Acesso em 08 abr. 2013.

BRASIL. Conselho Nacional de Educação. Parecer CNE/CEB 17/2001, de 17 de agosto de 2001. Brasília, 2001a. Disponível em http://portal.mec.gov.br/cne/arquivos/pdf/CEB017_2001.pdf. Acesso em: 08 abr. 2013. 


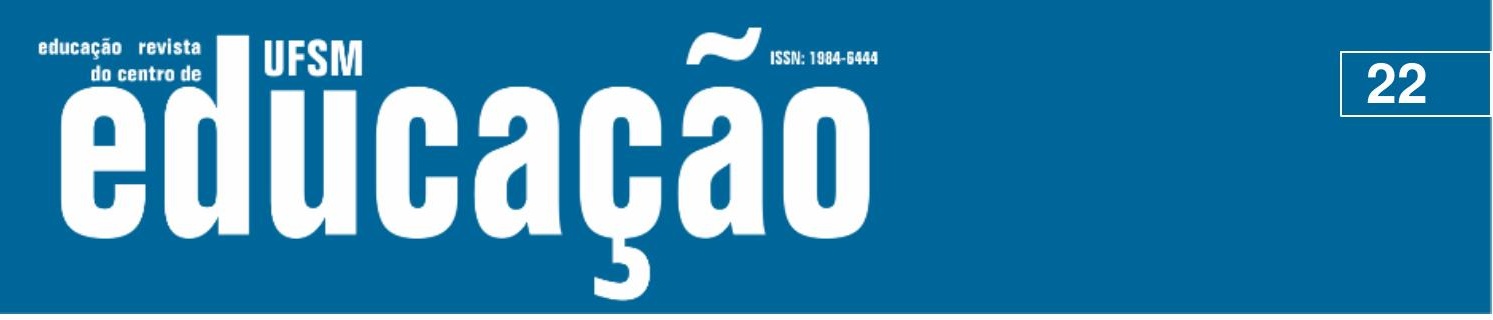

ISSN: 1984-6444 | http://dx.doi.org/10.5902/1984644440261

BRASIL. Conselho Nacional de Educação. Resolução CNE/CEB № 2, de 11 de setembro de 2001. Brasília, 2001b. Disponível em http://portal.mec.gov.br/cne/arquivos/pdf/CEB0201.pdf. Acesso em: 08 abr. 2013.

BRASIL. Congresso Nacional. Lei № 13.716, de 24 de setembro de 2018. Brasília, 2018. Disponível em http://www.planalto.gov.br/ccivil_03/_Ato20152018/2018/Lei/L13716.htm. Acesso em: 08 mar. 2019.

BRASIL. Ministério da Educação. Classe hospitalar e atendimento pedagógico domiciliar: estratégias e orientações. Brasília, dez. 2002. 35 p. Disponível em: http://portal.mec.gov.br/seesp/arquivos/pdf/livro9.pdf Acesso em: 08 mar. 2018.

BRASIL. Decreto № 6.571, de 17 de setembro de 2008. Brasília, 2008a. Disponível em http://www.planalto.gov.br/ccivil_03/_ato2007-2010/2008/Decreto/D6571.htm. Acesso em: 10 mai. 2014.

BRASIL. Ministério da Educação. Política Nacional de Educação Especial. Brasília, 2008b. 19 p. Disponível em: http://portal.mec.gov.br/index.php?option=com_docman\&view=download\&alias=1669 0-politica-nacional-de-educacao-especial-na-perspectiva-da-educacao-inclusiva05122014\&ltemid=30192 Acesso: 18 abr. 2018.

BRASIL. Conselho Nacional de Educação. Parecer CNE/CEB ํō 13/2009, aprovado em 03 de junho de 2009 - Diretrizes Operacionais para o atendimento educacional especializado na Educação Básica, modalidade Educação Especial. Brasília, 2009a. Disponível em http://portal.mec.gov.br/dmdocuments/pceb013_09_homolog.pdf. Acesso em: 20 ago. 2014.

BRASIL. Conselho Nacional de Educação. Resolução nํㅜ 04/09, de 2 de outubro de 2009. Brasília, 2009b. Disponível em http://portal.mec.gov.br/dmdocuments/rceb004_09.pdf. Acesso em: 18 ago. 2019.

BRASIL. Congresso Nacional. Emenda Constitucional № 59, de 11 de novembro de 2009. Brasília, 2009c. Disponível em: http://www.planalto.gov.br/ccivil_03/Constituicao/Emendas/Emc/emc59.htm. Acesso em: 08 mar. 2019.

BRASIL. Decreto № 7.611, de 17 de novembro de 2011. Brasília, 2011a. Disponível em http://www.planalto.gov.br/ccivil_03/_Ato2011-2014/2011/Decreto/D7611.htm. Acesso em: 10 mai. 2014.

BRASIL. Decreto № 7.612, de 17 de novembro de 2011. Brasília, 2011b. Disponível em http://www.planalto.gov.br/ccivil_03/_Ato20112014/2011/Decreto/D7611.htm. Acesso em: 10 mai. 2014. 


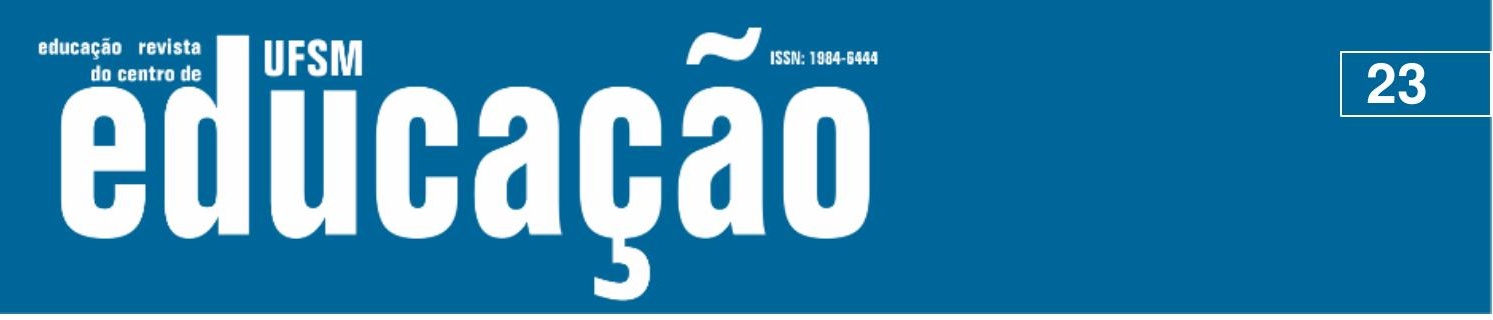

ISSN: 1984-6444 | http://dx.doi.org/10.5902/1984644440261

BRASIL. Congresso Nacional. Lei no 13.005, de 25 junho de 2014. Disponível em http://presrepublica.jusbrasil.com.br/legislacao/125099097/lei-13005-14 Acesso em: 30 jun. 2014.

BRASIL. Secretaria do Conselho de Desenvolvimento Econômico e Social (SEDES) da Casa Civil da Presidência da República. As Desigualdades na Escolarização no Brasil: Relatório de Observação n. 5. Brasília: Presidência da República, Conselho de Desenvolvimento Econômico e Social - CDES, 2014. 60 p. Disponível em: https://www.ufrgs.br/ppgeducacaociencias/ppgec/wpcontent/uploads/2018/10/CDES_Relato\%CC\%81rio_de_Observac\%CC\%A7a\%CC\% 83o_5_2014.pdf Acesso em: 15 jan. 2015.

BRASIL. Senado Nacional. Projeto de Lei 548. Altera a Lei no 9.394, de 20 de dezembro de 1996, que dispõe sobre as diretrizes e bases da educação nacional, para dispor sobre o atendimento educacional especializado em classes hospitalares ou mediante atendimento pedagógico domiciliar. 2015. Disponível em: http://www25.senado.leg.br/web/atividade/materias/-/materia/122761. Acesso em: 12 mar. 2019.

CHAUÍ, Marilena. Direitos Humanos e medo. In: Direitos Humanos e. São Paulo, Comissão de Justiça e Paz: Editora Brasiliense, 1989.

CRAHAY, Marcel. Poderá a escola ser justa e eficaz? Da igualdade das oportunidades à igualdade dos conhecimentos. Lisboa, Instituto Piaget, 2000.

CURY, Carlos Roberto Jamil. Direito à educação: direito à igualdade, direito à diferença. Cadernos de Pesquisa, São Paulo, n.116, p.245-262, jul. 2002.

DUARTE, Clarice Seixas. Direito público subjetivo e políticas educacionais. São Paulo em Perspectiva, São Paulo, n.18 (2), p. 113-118, 2004.

FONSECA, Eneida Simões da. A situação brasileira do atendimento pedagógicoeducacional hospitalar. Educação e Pesquisa. São Paulo, vol.25 n.1 São Paulo, Jan./Jun. 1999. Disponível em: http://www.scielo.br/scielo.php?pid=S151797021999000100009\&script=sci_arttextAc esso em: 23 mar. 2013.

FONSECA, Eneida Simões da. Atendimento escolar no ambiente hospitalar. São Paulo: Memnon, 2003.

MENEZES, Cinthya Vernizi Adachi de. Rumos de uma política pública. In: Escolarização Hospitalar: educação e saúde de mãos dadas para humanizar. Petrópolis, RJ: Vozes, 2009, p.23-34.

MENEZES, Cinthya Vernizi Adachi de. Atendimento Escolar Hospitalar e Domiciliar: estudo comparado das políticas educacionais do Paraná/Brasil e da Galícia/Espanha. Tese (Doutorado) Programa de Pós-Graduação em Educação, Setor de Educação, Universidade Federal do Paraná. Curitiba. 2018. 


\section{N Hism

ISSN: 1984-6444 | http://dx.doi.org/10.5902/1984644440261

circunstância de cuidado com a saúde, mas continua pertencente ao grupo de alunos da Educação Básica obrigatória."

2 Professora Associada com dedicação exclusiva no Departamento de Estudos da Educação Inclusiva e Continuada (DEIC) da Faculdade de Educação (EDU) da Universidade do Estado do Rio de Janeiro (UERJ). É membro da Rede Latino Americana e do Caribe pelo Direito à Educação de Crianças e Jovens Hospitalizados ou Impossibilitados de Frequentar Escola por Motivos de Doença (REDLACEH) com sede no Chile e da Organização Europeia de Pedagogos em Hospitais (HOPE).

${ }^{3} 2000$ no Rio de Janeiro - RJ; 2002 em Goiânia - GO, 2004 em Salvador - BA; 2005 em Porto Alegre - RS; 2007 em Curitiba - PR; 2009 em Niterói - RJ, com a participação da "Rede Latinoamericana e do Caribe pelo Direito à Educação da Criança ou Jovem Hospitalizado ou em Tratamento", com sede em Santiago, no Chile; 2012, em Belém - PA; em 2014, na cidade de São Paulo - SP; 2017 em Curitiba; 2019, a ser realizado em Salvador - BA.

${ }^{4}$ Constituição Federal (BRASIL, 1988); a Lei de Diretrizes e Bases da Educação Nacional (BRASIL, 1996); o Estatuto da Criança e do Adolescente (ECA) (BRASIL, 1990); Resolução no 41 do Conselho Nacional dos Direitos da Criança e do Adolescente (CONANDA) (BRASIL,1995) e o Plano Nacional de Educação (Lei No. 13005/14).

${ }^{5}$ Serviço destinado a prover, mediante atendimento especializado, a educação escolar a alunos impossibilitados de frequentar as aulas em razão de tratamento de saúde que implique internação hospitalar ou atendimento ambulatorial. (BRASIL, 2001, p. 51).

${ }^{6}$ Serviço destinado a viabilizar, mediante atendimento especializado, a educação escolar de alunos que estejam impossibilitados de frequentar as aulas em razão de tratamento de saúde que implique permanência prolongada em domicílio (BRASIL, 2001, p. 52).

${ }^{7}$ A Secretaria de Educação Especial (SEESP) do MEC foi incorporada pela atual Secretaria de Educação Continuada, Alfabetização, Diversidade e Inclusão (SECADI). 